\title{
Reversible shift from excitonic to excimer emission in fluorescent organic light emitting diodes: Dependence on deposition parameters and electrical bias
}

Anjaly Soman ${ }^{a, b}$, Anjali K. Sajeev ${ }^{a, b}$, Kavya Rajeev ${ }^{a, b}$ K. N. Narayanan Unni ${ }^{a, b^{*}}$

${ }^{\text {a }}$ Photosciences and Photonics Section, Chemical Sciences and Technology Division, CSIR-

National Institute for Interdisciplinary Science and Technology, Thiruvananthapuram, Kerala 695019, India

b Academy of Scientific and Innovative Research, Ghaziabad-201002, India

\section{Supporting Information}

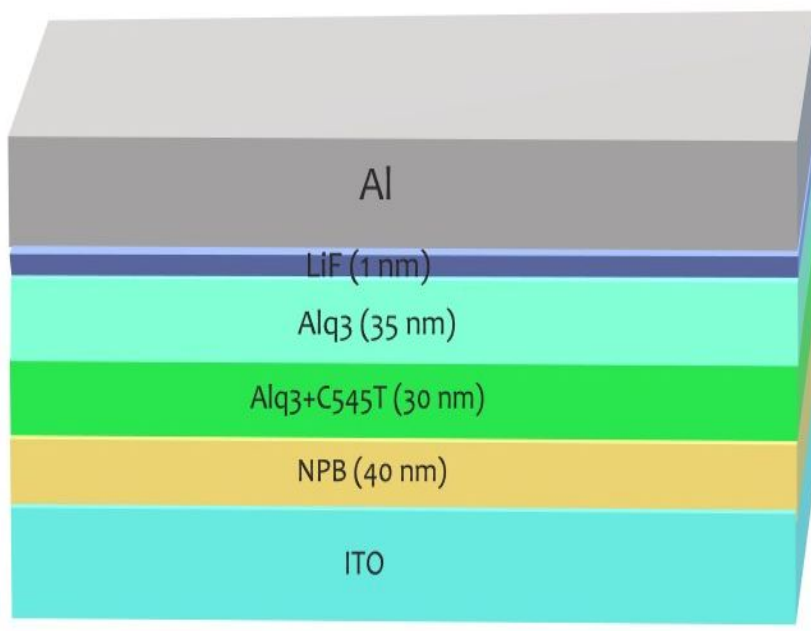

Figure S1. The schematic of the OLED device structure 


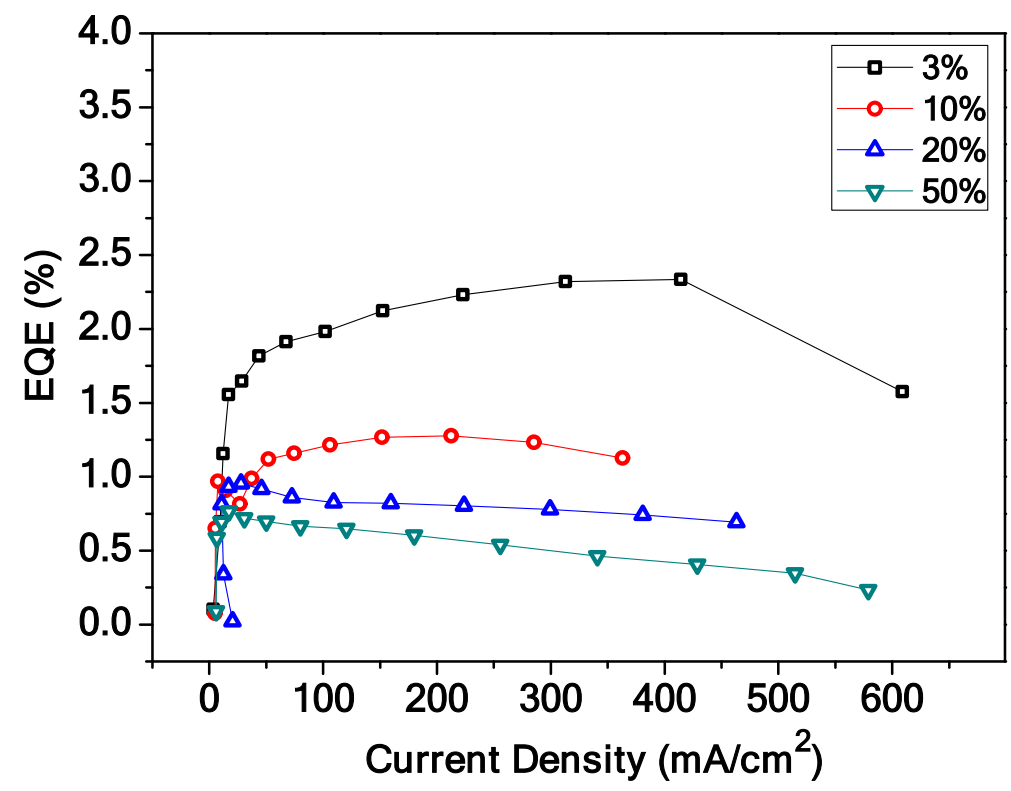

Figure S2. Variation of External quantum efficiency with current density for $\mathrm{Alq}_{3}: \mathrm{C} 545 \mathrm{~T}$ OLEDs with different doping $\%$.

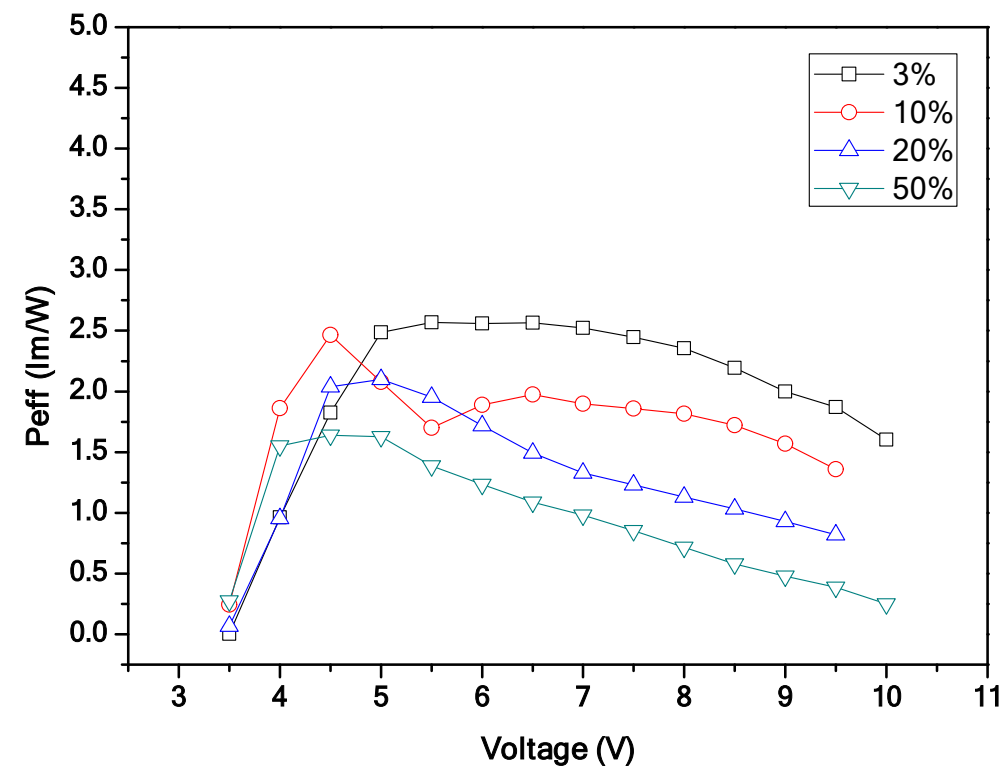

Figure S3. Variation of power efficiency with voltage for $\mathrm{Alq}_{3}: \mathrm{C} 545 \mathrm{~T}$ OLEDs with different doping $\%$. 


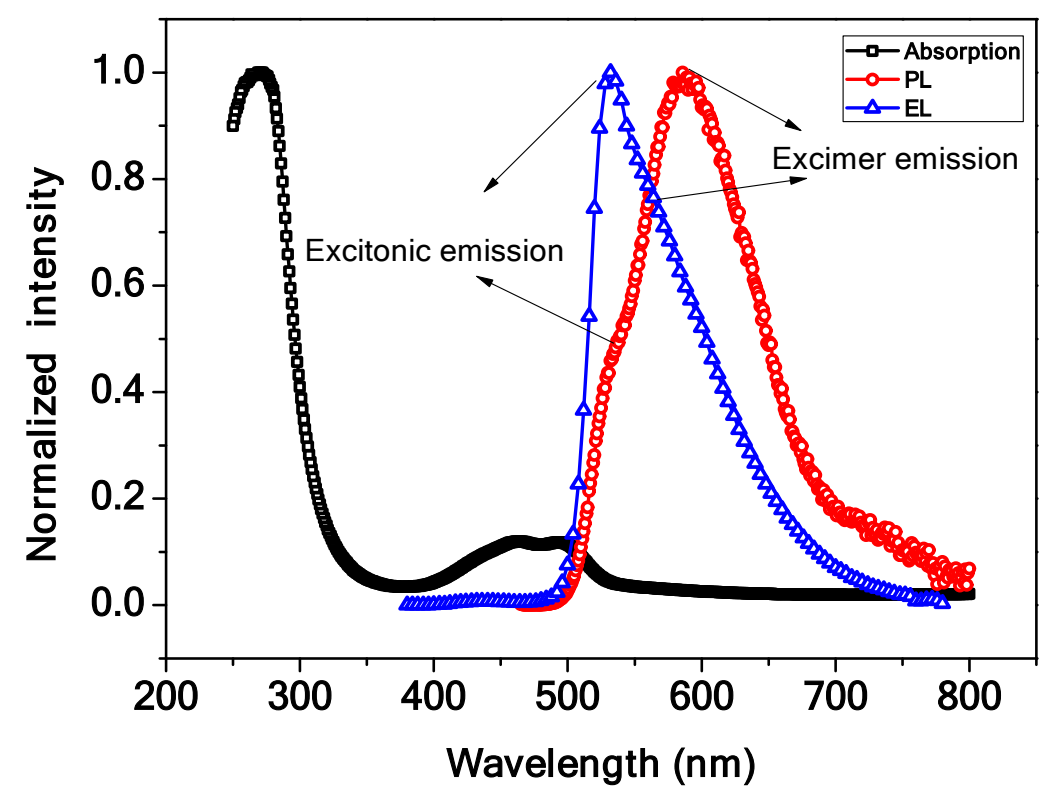

Figure S4. Absorption, photoluminescence and electroluminescence of C545T film of thickness 30 $\mathrm{nm}$

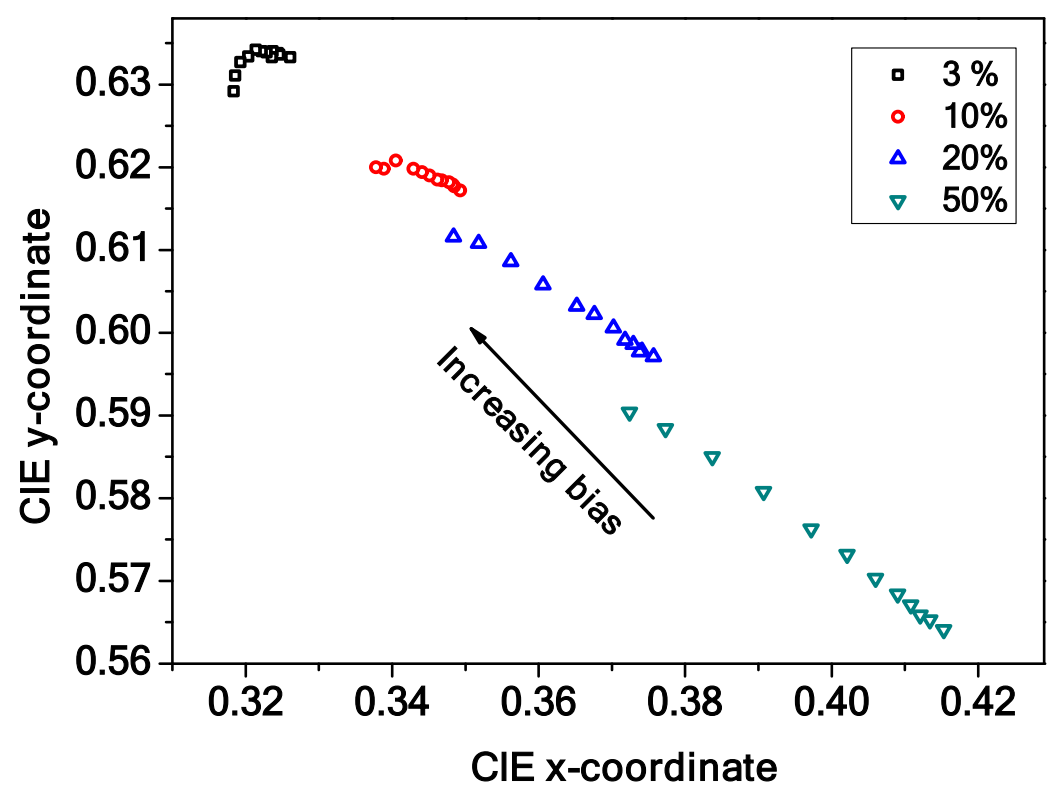

Figure S5. Variation of CIE coordinates $(\mathrm{x}, \mathrm{y})$ with increasing bias for Alq3:C545T devices with different doping concentration 


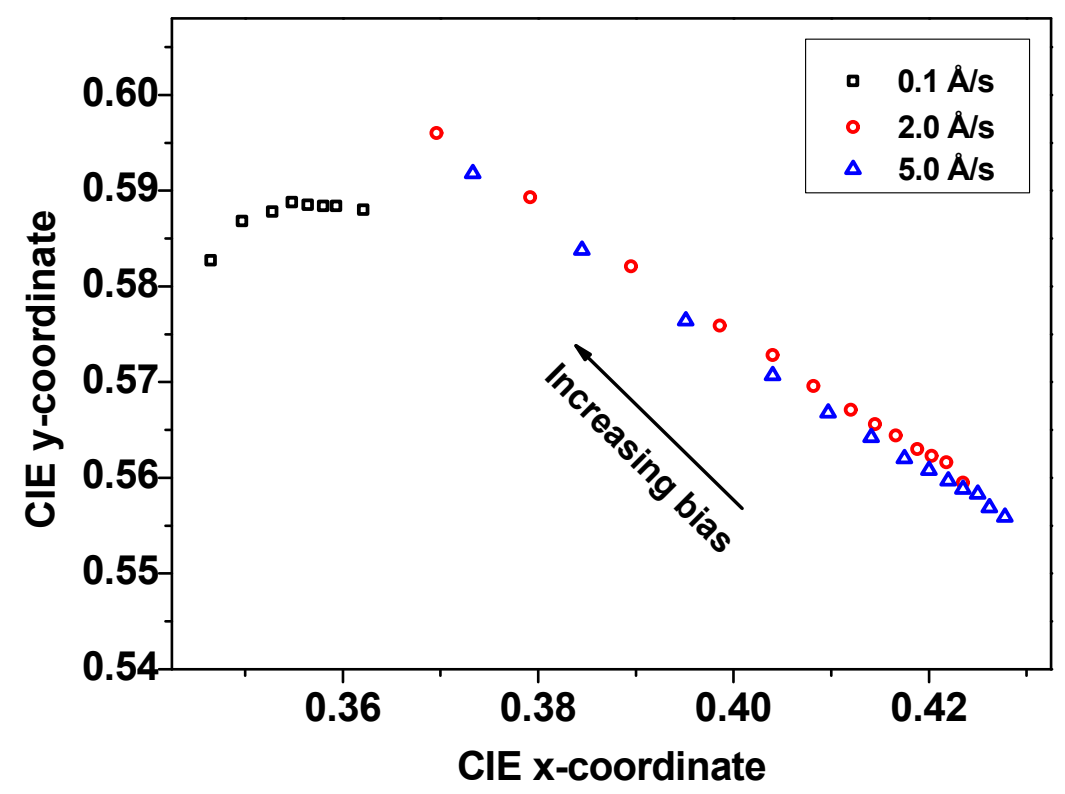

Figure S6. Variation of CIE coordinates (x,y) with increasing bias for C545T devices with different rates of evaporation

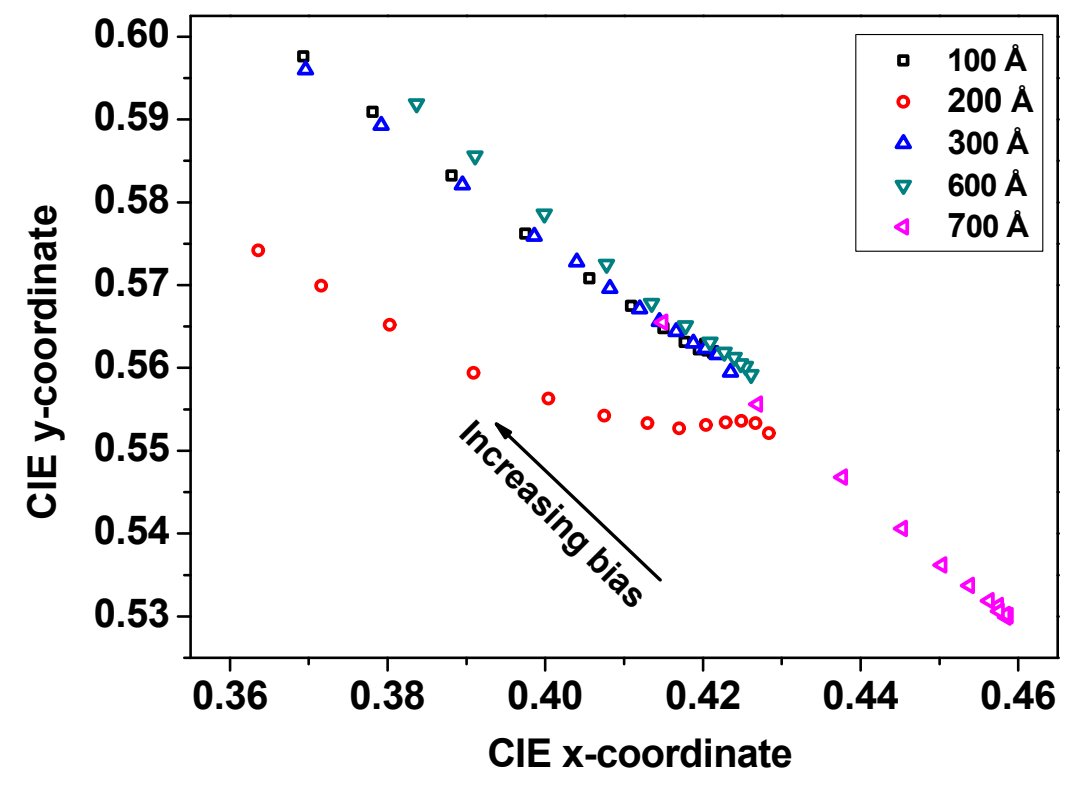

Figure S7. Variation of CIE coordinates (x,y) with increasing bias for C545T devices with different thicknesses 